Short Communication

\title{
DEVELOPMENT AND VALIDATION OF DOUBLE DIVISOR RATIO SPECTRA DERIVATIVE SPECTROPHOTOMETRY METHOD FOR TERNARY MIXTURE OF DEXTROMETHORPHAN HYDROBROMIDE, DOXYLAMINE SUCCINATE AND PSEUDOEPHEDRINE HYDROCHLORIDE IN TABLET DOSAGE FORM
}

\author{
RIDA EVALINA TARIGAN", MUCHLISYAM1*, SITI MORIN SINAGA', ZUL ALFIAN²
}

${ }^{1}$ Department of Pharmaceutical Chemistry, Faculty of Pharmacy, Universitas Sumatera Utara, Medan, 20155, Indonesia, ${ }^{2}$ Department of Chemistry, Faculty of Mathematics and Natural Sciences, Universitas Sumatera Utara, Medan, 20155, Indonesia

Email: muchlisyam@usu.ac.id

Received: 14 Jul 2020, Revised and Accepted: 29 Sep 2020

\begin{abstract}
This study aimed to develop spectrophotometry method by double divisor ratio spectra derivative to determine the levels of dextromethorphan hydrobromide (DEX), doxylamine succinate (DOX) and pseudoephedrine hydrochloride (PSE) in tablet dosage form using ethanol as solvent. The method is based on the use of the coincident spectra of the derivative of the ratio spectra obtained using a double divisor and measuring at the wavelengths selected. Then, the method was applied to determine the levels of DEX, DOX and PSE in tablet dosage form. The selected wavelengths for determination of DEX, DOX and PSE are $277.0 \mathrm{~nm}, 243.0 \mathrm{~nm}$, and $243.2 \mathrm{~nm}$, respectively. The mean \% recoveries were found to be in $100.88 \%$, $100.05 \%$, and $100.26 \%$ for DEX, DOX and PSE, respectively. The method is successfully applied to analyze DEX, DOX and PSE in pharmaceutical formulation with no interference from excipients as indicated by the recovery study. All validation parameters were within the acceptable range.
\end{abstract}

Keywords: Dextromethorphan hydrobromide, Doxylamine succinate, Pseudoephedrine hydrochloride, Spectrophotometry, Double divisor ratio spectra derivative

(C) 2020 The Authors. Published by Innovare Academic Sciences Pvt Ltd. This is an open access article under the CC BY license (http://creativecommons.org/licenses/by/4.0/) DOI: http://dx.doi.org/10.22159/ijap.2020v12i6.39037. Journal homepage: https://innovareacademics.in/journals/index.php/ijap

Dextromethorphan hydrobromide (DEX) is an antitussive agent commonly used in cough and cold preparations. DEX is chemically known as 3-methoxy-17-methyl- $(9 \alpha, 13 \alpha, 14 \alpha)$ morphinan hydrobromide monohydrate [1,2]. Doxylamine succinate (DOX) is an antihistamine used to relieve symptoms of allergy and the common cold. DOX is chemically known as N,N-dimethyl-2-[1phenyl-1-(2-pyridinyl)ethoxy]-butanedioate [2, 3]. Pseudoephedrine hydrochloride (PSE) is a nasal decongestant and also as bronchodilation. PSE is chemically known as $(1 \mathrm{~S}, 2 \mathrm{~S})-2$ methylamino1-phenylpropan-1-ol hydrochloride [4-6].

Reported methods for estimation of DEX individually and in combination with other drugs from bulk and its formulation include HPLC [7-9], RP-HPLC [10-12], spectrophotometry [13-15], HPTLC [16]. DOX was determined individually and in combination with other drugs from bulk and its formulation include RP-HPLC [17-19], spectrophotometry [20-22]. PSE was determined individually and in combination with other drugs from bulk and its formulation include RP-HPLC [23], spectrophotometry [24-26], TLC-densitometric [27].

Double divisor ratio spectra derivative spectrophotometry method for simultaneous estimation is simpler, rapid, accurate, and economic [28-30]. However, no references have been found for simultaneous estimation of DEX, DOX and PSE in their combined tablet dosage form by double divisor ratio spectra derivative spectrophotometry method. So, the objective is to develop double divisor ratio spectra derivative spectrophotometry method for estimation of DEX, DOX and PSE in the combined tablet dosage form.

Standard of DEX, DOX, PSE were from the National Agency of Drug and Food Control of the Republic of Indonesia, Ethanol (E. Merck), raw material of DEX, DOX and PSE from PT. Konimex, Sukoharjo, Central Java, Indonesia.

Ultraviolet-visible spectrophotometer (Shimadzu 1800, Japan), a set of Personal Computers (PC) equipped with UV-Probe 2.42 software

Accurately weighed $50 \mathrm{mg}$ of DEX, DOX and PSE standard was separately transferred into $50 \mathrm{ml}$ volumetric flask and dissolved in ethanol to give solutions containing $1000 \mu \mathrm{g} / \mathrm{ml}$ DEX, DOX and PSE.
The solutions of DEX, DOX and PSE were prepared in diluent by appropriate dilution and spectrum was recorded. The absorption spectra of the solutions prepared at different concentrations of DEX (40$430 \mu \mathrm{g} / \mathrm{ml})$, DOX $(20-430 \mu \mathrm{g} / \mathrm{ml})$, and PSE $(230-630 \mu \mathrm{g} / \mathrm{ml})$ were scanned in the range of $200-400 \mathrm{~nm}$. The double divisor value in various concentrations is calculated to selected wavelength range analysis.

Content of 20 tablets was weighed accurately. A powder quantity equivalent to $15 \mathrm{mg}$ DEX, $4 \mathrm{mg}$ DOX and $30 \mathrm{mg}$ PSE was accurately weighed and transferred into a volumetric flask of $25 \mathrm{ml}$ capacity; 15 $\mathrm{ml}$ of ethanol was transferred into this volumetric flask and sonicated for $10 \mathrm{~min}$. The flask was shaken and volume was made up to the mark with diluent. Filtered, pipette $1.16 \mathrm{ml}$ of the filtrate and transfer to a $10 \mathrm{ml}$ volumetric flask. filled with ethanol to the mark line to obtain a solution containing $70 \mu \mathrm{g} / \mathrm{ml}$ of DEX, $40 \mu \mathrm{g} / \mathrm{ml}$ of DOX, and $430 \mu \mathrm{g} / \mathrm{ml}$ of PSE. The resulting solution was analyzed by proposed method. The quantitation was carried out by keeping these values to the straight-line equation of calibration curve.

The methods were validated as per International Conference of Harmonization ( $\mathrm{ICH}$ ) guidelines with respect to linearity, accuracy, precision, limit of detection (LOD) and limit of quantitation (LOQ) [31].

Selection of analytical wavelength is carried out by dividing absorption spectra of solutions at different concentrations using the sum of the absorption spectra of solutions of DOX+PSE $(430 \mu \mathrm{g} / \mathrm{ml}$ each in diluents), DEX+PSE (430 $\mu \mathrm{g} / \mathrm{ml}$ each in diluents), and DEX+DOX (430 $\mu \mathrm{g} / \mathrm{ml}$ each in diluents), respectively, for the determination of DEX, DOX, and PSE as double divisor to get the ratio spectra and their first derivatives were plotted with delta lambda $2 \mathrm{~nm}$ and scaling factor 1.0. The divided and derivatized spectra's as shown in fig. 1-3.

Based on fig. 1-3, we can conclude that DEX, DOX and PSE can be quantitatively determined at wavelength $277.0 \mathrm{~nm}, 243.0 \mathrm{~nm}, 243.2$ $\mathrm{nm}$, respectively in their ternary mixture without any interference from each other. According to this result, the double divisor ratio spectra derivative spectrophotometry method can be used to simultaneously determine the drug content consisting of more than one component $[29,32]$.

The method was validated based on linearity, accuracy, precision, LOD and LOQ. The validation results are shown in table 1. 


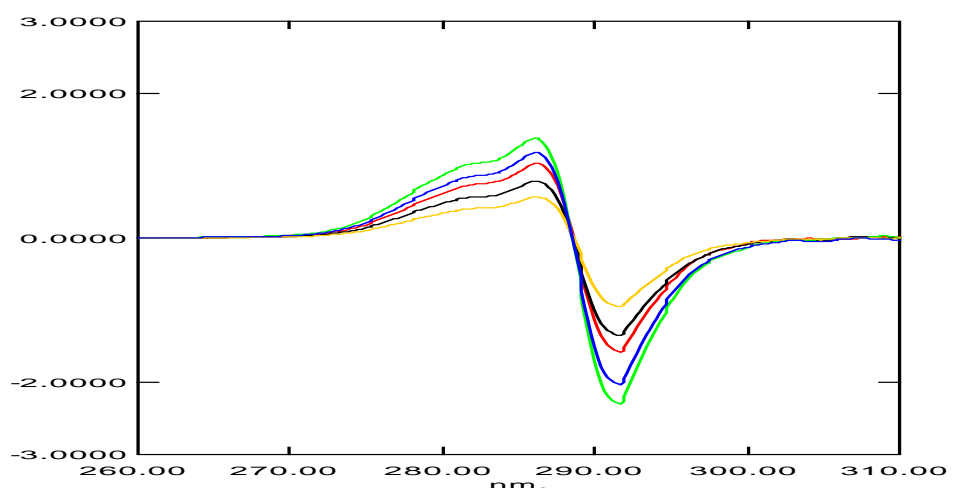

Fig. 1: Overlay first derivative ratio spectra of DEX at $277.0 \mathrm{~nm}$ (DOX $430 \mu \mathrm{g} / \mathrm{ml}+\mathrm{DOX} 430 \mu \mathrm{g} / \mathrm{ml}$ used as double divisor)

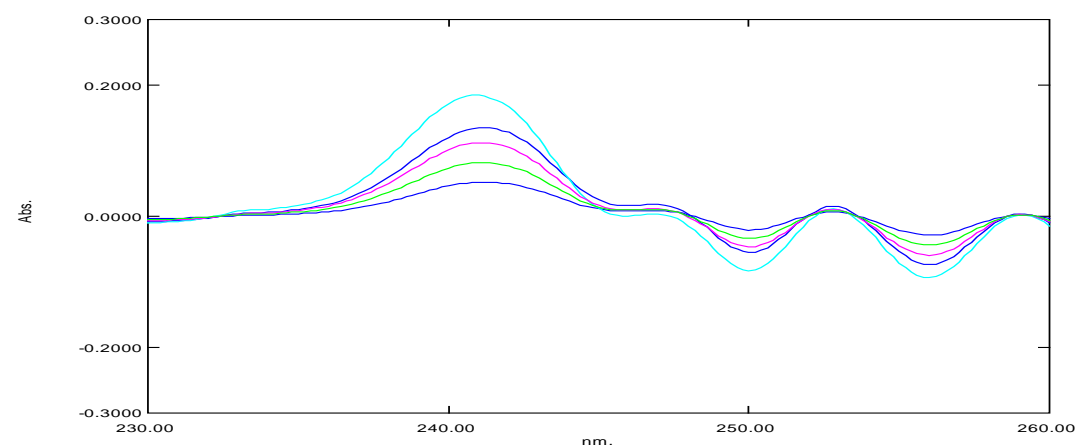

Fig. 2: Overlay first derivative ratio spectra of DOX at $243.0 \mathrm{~nm}$ (DEX $430 \mu \mathrm{g} / \mathrm{ml}+\mathrm{PSE} 430 \mu \mathrm{g} / \mathrm{ml}$ used as double divisor)

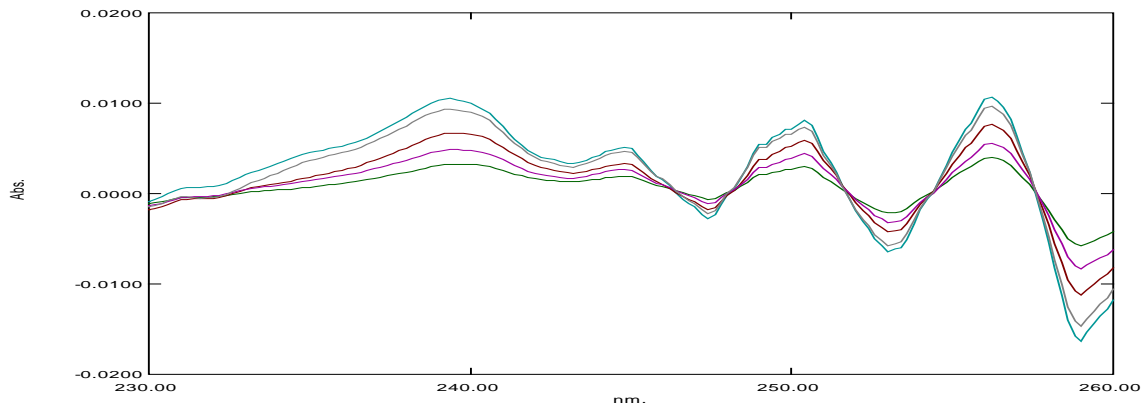

Fig. 3: Overlay first derivative ratio spectra of PSE at $243.2 \mathrm{~nm}$ (DEX $430 \mu \mathrm{g} / \mathrm{ml}+\mathrm{DOX} 430 \mu \mathrm{g} / \mathrm{ml}$ used as double divisor)

Table 1: Validation parameters for DEX, DOX and PSE

\begin{tabular}{llll}
\hline Parameters & DEX & DOX & PSE \\
\hline Linearity & 0.9997 & 0.9999 & 0.9983 \\
Accuracy $(\%)$ & 100.88 & 100.05 & 100.26 \\
Precision (\%) & 0.21 & 0.48 & 0.28 \\
LOD $(\mu \mathrm{g} / \mathrm{ml})$ & 2.9827 & 0.5715 & 44.7632 \\
LOQ $(\mu \mathrm{g} / \mathrm{ml})$ & 9.94 & 1.91 & 149 \\
\hline
\end{tabular}

Based on table 1, this research has good result validation method for simultaneous DEX, DOX and PSE in their combine tablet dosage form because all parameters of validation test have according to the validation requirements of ICH. It means the methods have appropriated the validation requirements. Some studies have been reported about spectrophotometry by double divisor ratio spectra derivative method and gave good validation method result $[29,30]$.

The proposed method was applied for the determination of DEX, DOX and PSE in their combined tablet and the results are shown in table 2.

Table 2: Statistical calculation of DEX, DOX and PSE in tablet dosage form

\begin{tabular}{llll}
\hline Component of drug & Statistical calculation & Content in etiquette & Level requirements \\
\hline DEX & $100.85 \pm 0.71 \%$ & $15 \mathrm{mg}$ & $(98-102) \%$ \\
DOX & $100.08 \pm 0.69 \%$ & $4 \mathrm{mg}$ & $(98-101) \%$ \\
PSE & $99.53 \pm 0.14 \%$ & $30 \mathrm{mg}$ & $(98-102) \%$ \\
\hline
\end{tabular}


Based on table 2, can be seen that the method of double divisor ratio spectra derivative have levels that meet requirements according to Indonesian Pharmacopeia Edition V. It means that the method can be used to simultaneous determine the mixture of DEX, DOX, and PSE in tablet dosage form. However, some studies have been reported [30], and according to this result, the proposed method is potential to use in routine drug analysis, especially drugs with contained the combination of several drugs.

The proposed method gives simpler, rapid, accurate, and precise results for determination of DEX, DOX and PSE as a ternary mixture without prior separation and is easily applied for routine analysis.

The authors are thankful to the Faculty of Pharmacy, Universitas Sumatera Utara, Medan, Indonesia on laboratory facilities to carry out the research work and PT. Konimex, Sukoharjo, Central Java, Indonesia for providing pure gift samples of dextromethorphan hydrobromide, doxylamine succinate and pseudoephedrine hydrochloride.

\section{FUNDING}

Nil

\section{AUTHORS CONTRIBUTIONS}

All the authors have contributed equally.

\section{CONFLICT OF INTERESTS}

Declared none

\section{REFERENCES}

1. Woo T. Pharmacology of cough and cold medicines. J Pediatr Health Care 2008;22:73-9.

2. Government of Indonesia. Indonesian Pharmacopoeia. 5th ed. Jakarta: Indonesian Health Ministry; 2014.

3. Eccless R, Fietze I, Rose UB. Rationale for treatment of common cold and flu with multi-ingredient combination products for multi-symptom relief in adults. Open J Respir Dis 2014;4:73-82.

4. Schoor JV. Colds, flu and coughing: a review of over-the-counter cold and flu medicines. S Afr Fam Pract 2013;55:334-6.

5. Schellack N, Labuschagne Q. Overview and management of colds and flu. S Afr Pharm J 2014;81:19-26.

6. Gelotte CK, Albrecht HH, Hynson J, Gallagher V. A multicenter, randomized, placebo-controlled study of pseudoephedrine for the temporary relief of nasal congestion in children with the common cold. J Clin Pharmacol 2019;59:1573-83.

7. Caglar H, Buyuktuncel E. HPLC method development and validation: simultaneous determination of active ingredients in cough and cold pharmaceuticals. Int J Pharm Pharm Sci 2014;6:421-8.

8. Sirigiri B, Chengalva P, Parameswari SA, Aruna G. A novel HPLC method for the simultaneous determination of chlorpheniramine maleate and dextromethorphan in bulk and pharmaceutical formulation. Int J Pharm Sci Res 2018;9:1147-51.

9. Al-Shaalan NH. Simultaneous determination of chlorphineramine maleate, dextromethorphan $\mathrm{HBr}$ and phenylephrin $\mathrm{HCl}$ in codilar syrup using high-performance liquid chromatography. J Pharm Sci Innov 2012;1:29-32.

10. Paidipala K, Kamarapu SK. Method development and validation of RP-HPLC method for simultaneous estimation of dextromethorphan hydrobromide, phenylephrine hydrochloride and triprolidine hydrochloride in bulk and combined tablets dosage forms. Int J Pharm Biol Sci 2013;3:172-9.

11. Bhortake PG, Lokhande RS. Simultaneous determination of acetaminophen, phenylephrine hydrochloride and dextromethorphan hydrobromide in liquicap dosage form by RP-HPLC. IJPRR 2014;3:9-14.

12. Mehta PS, Patel VB. RP-HPLC method for simultaneous estimation of bromohexine hydrochloride, dextromethorphan hydrobromide and guaiphenesin in soft gel capsules. Asian J Chem 2013;25:3341-3.

13. Chakraborthy B, Sivasubramanian L, Anusha. Simultaneous estimation of paracetamol, cetrizine and dextromethorphan using second derivative spectrophotometry. Int J Pharm Pharm Sci 2014;6:291-3.
14. Krunali T, Vijya $\mathrm{P}$, Rohit M, Meshram DB. UV spectrophotometric method for estimation of dextromethorphan in bulk and syrup formulation by area under the curve method. Int J Pharm Chem Sci 2013;2:1961-4.

15. Khanvilkar VV, Kothekar RR. Development and validation of simple UV spectrophotometric method for the estimation of dextromethorphan hydrobromide in bulk and marketed dosage formulations. Int J Pharm Sci Drug Res 2016;8:170-3.

16. Gandhi SV, Dyandyan SK. Development and validation of stability-indicating HPTLC method for estimation of dextromethorphan hydrobromide. J Appl Pharm Res 2017;5:27-33.

17. Kumar BP, Vidyadhara S, Murthy TEGK, Sasidhar RLC, Krishna VS. Development and validation of RP-HPLC method for simultaneous estimation of doxylamine succinate and pyridoxine hydrochloride in bulk and pharmaceutical dosage forms. Eurasian J Anal Chem 2017;12:459-68.

18. Richards P, Kumar VK. A new RP-HPLC method develop a new RP-HPLC method development and validation for simultaneous estimation of pyridoxine hydrochloride and doxylamine succinate in bulk drug and pharmaceutical tablet dosage form. IOSR J Pharm Biol Sci 2017;12:74-9.

19. Rosa PCP, Jardim ICSF. Simultaneous determination of clobutinol hydrochloride and doxylamine succinate from syrups by RP HPLC using a new stationary phase containing embedded urea polar groups. Braz J Pharm Sci 2012;48:31523.

20. Kasturi AK, Medicherla KR, Yaganti R, Balakrishnan N. Second derivative spectrophotometric method for simultaneous determination of doxylamine succinate and pyridoxine $\mathrm{HCl}$ in pharmaceutical formulations. Int J Life Sci Pharma Res 2019;9:10-5.

21. Premkumara S, Karunakaran A, Murugesan V, Munusamy J, Jayaprakash R, Murugesan R. Validated uv-spectrophotometric method for the simultaneous estimation of pyridoxine hydrochloride and doxylamine succinate in bulk and in the pharmaceutical dosage form. Adv J Chem A 2019;2:245-55.

22. Nayak SC, Kulkarni PV, Bhaskar V, Chavhan V. Development and validation of UV spectrophotometric method for simultaneous estimation of doxylamine succinate and pyridoxine hydrochloride in bulk and tablet dosage form. Int J Pharm Pharm Sci 2013;5:390-3.

23. Rawool ND, Venkatchalam A, Singh KH. Development and validation of a rapid RP-HPLC method for the simultaneous estimation of cetrizine and pseudoephedrine in pharmaceutical dosage forms. Int J Curr Pharm Res 2013;5:54-60.

24. Balamurugan K, Gokulakrishnan K. Spectrophotometric method for the determination of pseudoephedrine in bulk and formulations. Anal Chem Ind J 2011;10:390-3.

25. Souri E, Rahimi A, Ravari NS, Tehrani MB. Development of a rapid derivative spectrophotometric method for simultaneous determination of acetaminophen, diphenhydramine and pseudoephedrine in tablets. Iran J Pharm Res 2015;14:435-42.

26. Reid IOA, Widaa TA. Spectrophotometric method for the simultaneous determination of pseudoephedrine and triprolidine in bulk and tablet forms. IJAPA 2017;7:21-3.

27. El-Kommos ME, El-Gizawy SM, Atia NN, Hosny NM. Thin-layer chromatography-densitometric determination of some nonsedating antihistamines in combination with pseudoephedrine or acetaminophen in synthetic mixtures and in pharmaceutical formulations. Biomed Chromatogr 2014;28:391-400.

28. Rafat MN, Mahmoud MI, Alaa AS, Nahed TS. Double divisor means centering of ratio spectra as a developed spectrophotometric method for the analysis of five-component. J Saudi Chem Soc 2017;21:S283-S92.

29. Gohel RV, Parmar SJ, Patel BA. Development and validation of double divisor-ratio spectra derivative spectrophotometric method for simultaneous estimation of olmesartan medoxomil, amlodipine besylate and hydrochlorthiazide in tablet dosage form. Int J PharmTech Res 2014;6:1518-25.

30. Abdelwahab NS, Abdelaleem EA. Application of fourier function to double divisor ratio spectra curves for analysis of some amoebicide drugs in their ternary mixtures. Pharm Anal Acta 2012;3:1-7. 
31. Ermer J, Miller JH. Method validation in pharmaceutical analysis. A guide to best practice. Weinheim: Wiley-Vch Verlag $\mathrm{GmBH}$ and Co. KGaA; 2005.
32. Sowjanya G, Ganapaty S, Almas S. Derivative UV spectroscopic approaches in multicomponent analysis-a review. Int J Pharm Pharm Sci 2019;11:1-11. 